\title{
Picrophilus oshimae and Picrophilus torridus fam. nov., gen. nov., sp. nov., Two Species of Hyperacidophilic, Thermophilic, Heterotrophic, Aerobic Archaea
}

\author{
CHRISTA SCHLEPER, GABRIELA PÜHLER, HANS- PETER KLENK, \\ AND WOLFRAM ZILLIG*
}

Max Plank Institut für Biochemie, D-82152 Martinsried, Germany

\begin{abstract}
We describe two species of hyperacidophilic, thermophilic, heterotrophic, aerobic archaea that were isolated from solfataric hydrothermal areas in Hokkaido, Japan. These organisms, Picrophilus oshimae and Picrophilus torridus, represent a novel genus and a novel family, the Picrophilaceae, in the kingdom Euryarchaeota and the order Thermoplasmales. Both of these bacteria are more acidophilic than the genus Thermoplasma since they are able to grow at about $\mathrm{pH}$.
\end{abstract}

The moderately thermophilic, hyperacidophilic, aerobic archaea (archaebacteria) (7) Picrophilus oshimae and Picrophilus torridus, which have been described previously $(4,5)$, were isolated from moderately hot hydrothermal areas in solfataric fields in Hokkaido, Japan. One of the sources of isolation was a solfataric spring which had a temperature of $53^{\circ} \mathrm{C}$ and a $\mathrm{pH}$ of 2.2 , and the other was a rather dry hot soil which had a $\mathrm{pH}$ of $<0.5$. Pure strains (strains DSM $9789^{\mathrm{T}}$ [T $=$ type strain] and DSM 9790, respectively) were obtained from single colonies that grew in 4 days at $60^{\circ} \mathrm{C}$ on $12.5 \%$ starch gels containing 2 $\mathrm{g}$ of yeast extract per liter at $\mathrm{pH} 1$.

Both organisms utilize 1 to $5 \mathrm{~g}$ of yeast extract per liter as a carbon source by respiration and appear to be unable to grow by fermentation or chemolithoautotrophically by formation of $\mathrm{H}_{2} \mathrm{~S}$ from sulfur and hydrogen or by sulfur respiration. They grow at about $\mathrm{pH} 0$ and optimally at $\mathrm{pH} 0.7$; and they grow at 47 to $65^{\circ} \mathrm{C}$ and optimally at $60^{\circ} \mathrm{C}$.

As determined by an analysis of $16 \mathrm{~S}$ rRNA sequences, the closest relative of these organisms is Thermoplasma acidophilum, but $P$. oshimae and $P$. torridus are sufficiently distinct to be considered representatives of a different family, the Picrophilaceae, in the order Thermoplasmales. These bacteria can be distinguished by their growth characteristics, especially their hyperacidophilia, by the presence of a filigree tetragonal $\mathrm{S}$ layer, and by the presence of an RNA polymerase that has a different subunit pattern and does not cross-react with an antibody against the RNA polymerase of $T$. acidophilum in the immunodiffusion assay of Ouchterlony (8). On a phylogenetic tree based on 16S rRNA sequences in which transitions are neglected, members of the order Thermoplasmales, including the genus Picrophilus, form a deep branch in the kingdom Euryarchaeota between the Thermococcales and the methanogens, which is consistent with the position of the genus Thermoplasma on phylogenetic trees based on the large components of DNA-dependent RNA polymerase.

A detailed description of the genus Picrophilus, including the phylogeny of this taxon and its growth characteristics, is given elsewhere.

Description of Picrophilaceae Schleper, Zillig, and Pühler fam. nov. Picrophilaceae (Pi.cro.phi.la' ce.ae. Gr. adj. pikros, sour, acidic, sharp; Gr. adj., philos, loving; L. ending aceae, family; Picrophilaceae, acid-loving family) is another family belonging to the order Thermoplasmales besides the Thermoplasmaceae which comprises acid-loving (i.e., hyperacidophilic) organisms. Separation of these taxa is justified by their phylogenetic distance, $(9.5 \%$ difference in the $16 \mathrm{~S}$ rRNA sequences of members of the Picrophilaceae and $T$. acidophilum), by the lack of immunochemical cross-reactions in Ouchterlony immunodiffusion assays between the RNA polymerases of $P$. oshimae and $T$. acidophilum, which also do not occur between members of the closely related families Thermoproteaceae and Thermophilaceae, and by the presence of an S layer in the genus Picrophilus but not in the genus Thermoplasma.

Description of Picrophilus, Schleper, Zillig, and Pühler gen. nov. Picrophilus (Pi.cro.phi' lus. Gr. adj. pikros, acidic; Gr. adj. philos, loving; N. L. masc. n. Picrophilus, acid-loving organism). Obligately aerobic, heterotrophic, moderately thermophilic, hyperacidophilic, irregular cocci. Different dividing states occur beside each other, as determined by microscopic examination (Fig. 1). Grows at temperatures between 47 and $65^{\circ} \mathrm{C}$ and optimally at $60^{\circ} \mathrm{C}$. Grows at $\mathrm{pH}$ values between about 0 and 3.5 and optimally at $\mathrm{pH} 0.7$. Grows in the presence of 0.1 to $0.5 \%$ yeast extract and optimally in the presence of $0.2 \%$ yeast extract; a lag phase occurs in the presence of $0.5 \%$ yeast extract. Under optimal conditions, the generation time is $6 \mathrm{~h}$. Slow

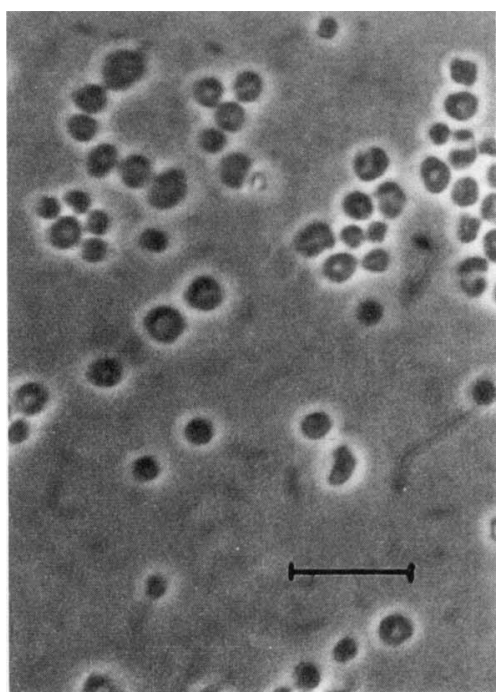

\footnotetext{
${ }^{*}$ Corresponding author.
}

FIG. 1. Phase-contrast micrograph of $P$. oshimae. Bar $=5 \mu \mathrm{m}$. 

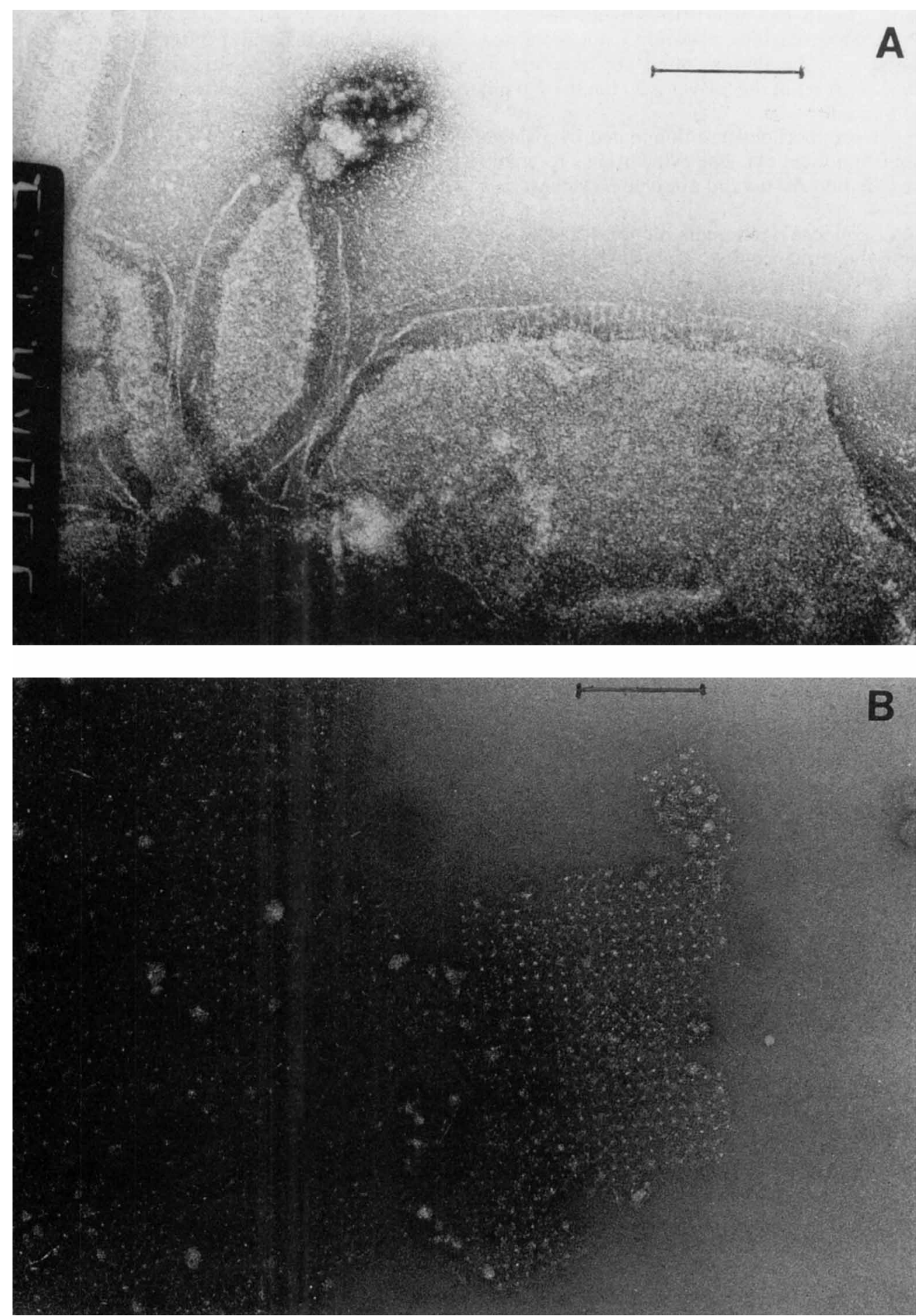

FIG. 2. (A) Electron micrograph of a cell of $P$. oshimae, showing a seam essentially representing a side view of the $\mathrm{S}$ layer. (B) Top view of a piece of an isolated $S$ layer. Both preparations were negatively contrasted with uranyl acetate. Both photographs were supplied by Ute Santarius and Wolfgang Baumeister. Bars $=0.2 \mu \mathrm{m}$.

growth to a low density occurs on tryptone, and no growth occurs on many other carbon sources.

The diameter of the cells is about $1 \mu \mathrm{m}$. Division occurs by constriction. The division intermediates resemble those of Thermococcus strains. There is a regular filigree teragonal $\mathrm{S}$ layer, which probably has polysaccharide chains on the outside (Fig. 2).
Two species are known, type species $P$. oshimae and $P$. torridus.

Description of type species Picrophilus oshimae Schleper, Zillig, and Pühler sp. nov. Picrophilus oshimae (o.shi' mae. M.L. gen. n. oshimae, of Oshima, referring to Japanese biochemist Tairo Oshima, who furnished invaluable help in organizing our collecting trip). 
Shape, size, and growth characteristics are as described above for the genus. Large cavities, apparently not separated from the cytoplasm by a membrane, often are observed in sections. The lattice constant of the $S$ layer is $20 \mathrm{~nm}(6)$. No pili or flagellae are observed.

The bis-phytanyl tetraetherlipids are dominated by a single phosphoglycolipid component (1). The cytochromes resemble those of the genus Thermoplasma and are type $b$ cytochromes (3).

The 16S rRNA sequence (accession number X84901) is 9.5\% different from the sequence of $T$. acidophilum and about $3 \%$ different from the sequence of $P$. torridus.

The $\mathrm{G}+\mathrm{C}$ content of the DNA is $36 \mathrm{~mol} \%$. The EcoRI restriction pattern of the DNA is similar to, but characteristically different from, that of $P$. torridus. Two different but partially homologous plasmids, one about $8.3 \mathrm{kbp}$ long and the other about $8.8 \mathrm{kbp}$ long, occur in some but not all strains. One strain contains both plasmids. The type strain is strain DSM 9789.

Description of Picrophilus torridus Zillig, Schleper, and Pühler sp. nov. Picrophilus torridus (tor' ri.dus. L. part. torridus, dried, burned, referring to the fact that the species was found in rather dry hot soil). The DNA restriction pattern resembles, but is clearly different from, that of $P$. oshimae; the 16S rRNA sequences of the two organisms differ by $3 \%$ at the 250 positions analyzed. At least as acidophilic as $P$. oshimae. Grows significantly faster than $P$. oshimae. No plasmid is present.

\section{REFERENCES}

1. Gambacorta, A. Personal communication.

2. Klenk, H.-P., and W. Zillig. 1994. DNA-dependent RNA polymerase subunit $B$ as a tool for phylogenetic reconstructions: branching topology of the archaeal domain. J. Mol. Evol. 38:420-432.

3. Schäfer, G. Personal communication.

4. Schleper, C., G. Pühler, I. Holz, D. Janekovic, U. Santarius, H.-P. Klenk, and W. Zillig. 1995. Picrophilus gen. nov., fam. nov.: a novel aerobic, heterotrophic, thermoacidophilic genus and family comprising archaea capable of growth around $\mathrm{pH}$ O. J. Bacteriol. 177:7050-7059.

5. Schleper, C., G. Pühler, B. Kühlmorgen, and W. Zillig. 1995. Life at extremely low pH. Nature (London) 375:741-742.

6. Volker-Mürkl, S. Personal communication.

7. Woese, C. R., O. Kandler, and M. L. Wheelis. 1990. Towards a natural system of organisms: proposal for the domains Archaea, Bacteria and Eucarya. Proc. Natl. Acad. Sci. USA 87:4576-4579.

8. Zillig, W., A. Gierl, G. Schreiber, S. Wunderl, D. Janekovic, K. O. Stetter, and H.-P. Klenk. 1983. The archaebacterium Thermofilum pendens represents a novel genus of the thermophilic, anaerobic sulfur respiring Thermoproteales. Syst. Appl. Microbiol. 4:79-87. 